Purdue University Purdue e-Pubs

2013

\title{
Metal Functionalization of Carbon Nanotubes for Enhanced Sintered Powder Wicks
}

\author{
A. S. Kousalya \\ Purdue University
}

JA. Weibel

Purdue University, jaweibel@purdue.edu

S V. Garimella

Purdue University, sureshg@purdue.edu

T. S. Fisher

Purdue University

Follow this and additional works at: http://docs.lib.purdue.edu/coolingpubs

Kousalya, A. S.; Weibel, J A.; Garimella, S V.; and Fisher, T. S., "Metal Functionalization of Carbon Nanotubes for Enhanced Sintered Powder Wicks" (2013). CTRC Research Publications. Paper 187.

http://dx.doi.org/http://dx.doi.org/10.1016/j.ijheatmasstransfer.2012.12.030

This document has been made available through Purdue e-Pubs, a service of the Purdue University Libraries. Please contact epubs@purdue.edu for additional information. 


\title{
Metal Functionalization of Carbon Nanotubes for Enhanced Sintered Powder Wicks
}

\author{
Arun S. Kousalya, Justin A. Weibel, Suresh V. Garimella, Timothy S. Fisher* \\ School of Mechanical Engineering and Birck Nanotechnology Center \\ Purdue University, West Lafayette, IN 47907, USA \\ * Corresponding author, Email address: tsfisher@purdue.edu, Tel.: +1 (765) 4945627
}

\begin{abstract}
Phase change cooling schemes involving passive heat spreading devices, such as heat pipes and vapor chambers, are widely adopted for thermal management of high heat-flux technologies. In this study, carbon nanotubes (CNTs) are fabricated on a $200 \mu \mathrm{m}$ thick sintered copper powder wick layer using a microwave plasma enhanced chemical vapor deposition technique. A physical vapor deposition process is used to coat the CNTs with a varying thickness of copper to promote surface wetting with the working fluid, water. Thermal performance of the bare sintered copper powder sample (without CNTs) and the copper-functionalized CNT-coated sintered copper powder wick samples is compared using an experimental facility that simulates the capillary fluid feeding conditions of a vapor chamber. A notable reduction in the boiling incipience superheat is observed for the nanostructured samples. Additionally, nanostructured samples having a thicker copper coating provided a considerable increase in dryout heat flux, supporting heat fluxes up to $457 \mathrm{~W} / \mathrm{cm}^{2}$ from a $5 \mathrm{~mm} \times 5 \mathrm{~mm}$ heat input area, while maintaining lower surface superheat temperatures compared to a bare sintered powder sample; this enhancement is attributed primarily to the improved surface wettability. Dynamic contact angle measurements are conducted to quantitatively compare the surface wetting trends for varying copper coating thicknesses and confirm the increase in hydrophilicity with increasing coating thickness.
\end{abstract}

Keywords: vapor chamber; heat pipe; carbon nanotube (CNT); dryout heat flux; boiling; surface functionalization

\section{NOMENCLATURE}

$A_{c} \quad$ heat input area, $\mathrm{m}^{2}$

$\mathrm{d}_{\mathrm{br}} \quad$ breakthrough bubble diameter, $\mathrm{m}$

$\mathrm{g} \quad$ acceleration due to gravity, $\mathrm{m} / \mathrm{s}^{2}$

$h_{f g} \quad$ heat of vaporization, $\mathrm{J} / \mathrm{kg}$

$k \quad$ thermal conductivity, W/mK

$q^{\prime \prime} \quad$ input heat flux, W/ $/ \mathrm{cm}^{2}$

Temperature, ${ }^{\circ} \mathrm{C}$

$t \quad$ thickness, $\mathrm{m}$

$\mathrm{V}_{\mathrm{cl}} \quad$ contact line velocity, $\mathrm{m} / \mathrm{s}$

$x \quad$ thermocouple location, $\mathrm{m}$

\section{Greek symbols}

$\varepsilon$

volumetric porosity 
$\theta_{\mathrm{a}} \quad$ equilibrium advancing contact angle, deg

$\theta_{\mathrm{r}} \quad$ equilibrium receding contact angle, deg

$\lambda_{\mathrm{u}} \quad$ instability wavelength on a surface with microscale coating, $\mathrm{m}$

$\rho \quad$ density, $\mathrm{kg} / \mathrm{m}^{3}$

$\sigma \quad$ surface tension, $\mathrm{N} / \mathrm{m}$

$\tau_{\mathrm{f}} \quad$ total droplet infiltration time, $\mathrm{s}$

\section{Subscripts}

$250 \mathrm{~nm}$

$750 \mathrm{~nm}$

bare

$\mathrm{CHF}$, porous

$\mathrm{Cu}$

dryout

$\mathrm{g}$

1

ref

$\mathrm{s}$

sat
Sintered powder sample with $250 \mathrm{~nm}$ copper coating on CNTs

Sintered powder sample with $750 \mathrm{~nm}$ copper coating on CNTs bare sintered powder sample (no CNTs)

Critical heat flux on a porous surface copper property

dryout heat flux

vapor

liquid

vapor reference temperature

solder

saturation temperature 


\section{Introduction}

Thermal analysis of three-dimensional circuit architectures, currently being developed for logic, memory, and opto-electronic device integration, points towards significantly higher waste heat energy densities and increased temperature non-uniformities in 3-D devices [1]. Adequate thermal management of these evolving chip architectures is therefore critical to maintaining acceptable device temperatures and improving the reliability and longevity of future electronic systems. Phase-change cooling schemes have emerged as a prominent thermal management solution because of their potential to achieve high heat dissipation rates while maintaining uniform device temperatures. Various cooling schemes with active liquid pumping, such as microchannel cooling [2, 3], jet impingement cooling $[4,5]$ and spray cooling [6], continue to be topics of intense research, and have considerably reduced the thermal resistance between the chip and the ambient when employing phase change [7]. However, implementation of pumped liquid cooling schemes is becoming increasingly difficult in real systems due to demanding space and weight constraints. In contrast, devices that employ passive phase-change cooling, such as heat pipes and vapor chambers, can be more easily incorporated into realistic systems for efficient heat removal.

The operating principle of a vapor chamber is analogous to that of a heat pipe; however, the term vapor chamber typically refers to spreading devices that spread heat from a small evaporator area to a large condenser surface over a short fluid working distance. In a typical vapor chamber, an optimized charge of working fluid is housed in a thin-walled copper shell at a reduced pressure corresponding to the desired operating saturation temperature. Evaporation/boiling occurs in a liquid-saturated porous wick structure lining the heated evaporator side. The resulting vapor pressure differential drives flow towards the condenser side. Capillary pressure passively transports the condensed working fluid back to the heat input area of the wick structure, closing the fluid-thermal cycle and allowing continuous removal of heat. Figure 1 depicts a schematic diagram of the internal transport processes in a vapor chamber with a sintered copper powder layer as the wick structure on the evaporator side; the sintered wick is coated with carbon nanotubes (CNTs) in the figure. Vapor chambers are relatively inexpensive, offer high reliability, and allow for packaging adaptability, making them an attractive and reliable solution for next-generation electronic systems. However, current-generation vapor chambers are limited by the maximum supported thermal loads and heat flux.

The maximum heat flux supported by a vapor chamber is dictated primarily by the liquid replenishment capability of the evaporator wick structure. The thermal resistance posed by the conduction path through the wick material and by phase change at the liquid-vapor interface is critical in determining the overall device resistance and the maximum amount of heat that can be transported by the vapor chamber. Hence, 
it is critical that a thorough understanding of the evaporative/boiling heat transfer mechanisms in the evaporator wick structure be obtained.

The boiling incipience superheat and the dryout heat flux constitute two important design criteria for a wick structure. With increasing temperature non-uniformities and the presence of local hot spots in dense circuit-packaging designs, operation of a vapor chamber in the boiling regime proves advantageous because of the enhanced heat transfer coefficients and lower overall thermal resistance associated with the wick structure [8]. Reduction of the surface superheat temperature at which the transition from evaporation to boiling occurs is desirable because it would provide operation in the boiling regime over a wider range of operational heat fluxes and avoid the temperature excursion associated with this transition. Extending the dryout heat flux, which is the maximum supported heat flux, to a level of $1 \mathrm{~kW} / \mathrm{cm}^{2}$ or greater [9] is decisive for thermal management of future electronic systems. A high-heat-flux vapor chamber should maximize the permeability of the wick to liquid flow to minimize the pressure drop, while simultaneously providing sufficient capillary pressure to draw enough liquid to the evaporator to support the maximum heat flux desired.

A number of studies dedicated to understanding the influence of wick parameters (such as wick thickness, sintered particle diameter and porosity) on thermal performance have imparted a good understanding of the respective performance trends for monoporous wicks that possess a single characteristic pore size [8, $10,11]$. Several modifications to traditional monoporous wicks have been proposed in prior work [12-16] to improve the dryout heat flux and to decrease the thermal resistance of the wick structure to meet the cooling requirements for ultra-high heat flux applications. Semenic and Catton [12] compared the critical heat flux (CHF) of monoporous and biporous wicks (wicks with two different pore sizes) using water as the working fluid, under sub-atmospheric saturation pressure $(<13 \mathrm{kPa})$ conditions and reported high CHF values of $520 \mathrm{~W} / \mathrm{cm}^{2}$ and $990 \mathrm{~W} / \mathrm{cm}^{2}$ at superheats of $50{ }^{\circ} \mathrm{C}$ and $147{ }^{\circ} \mathrm{C}$ for $800 \mu \mathrm{m}$ and $3000 \mu \mathrm{m}$ thick biporous wicks, respectively. They argued that monoporous wicks are not suitable for supporting high heat dissipation rates because as the pore size is decreased to yield improved capillary forces required at high heat fluxes, this also leads to more efficient vapor trapping and the prevent of liquid feeding; this supports local dryout. In contrast, the two characteristic pore sizes of biporous wicks may be optimized to provide adequate vapor release sites via the larger pores while maintaining sufficiently high capillarity to prevent dryout via the smaller pores. Nevertheless, thick biporous wicks may not find practical use due to the high wick resistance and the high resulting wall superheat. Zhao and Chen [13] investigated the thermal performance of sintered copper wicks with microgrooves in the direction of liquid flow of widths ranging from 150-500 $\mu \mathrm{m}$. Compared to a randomly distributed pattern of vapor exit 
pathways in biporous wicks, microgrooves provided aligned passages for vapor to exit the wick, and extended the CHF by as much as $350 \%$ compared to monoporous wicks.

Nanostructuring of the heat transfer surface has been pursued as an alternate approach for achieving superior thermal performance in pool boiling and vapor chambers. Nanostructuring could provide an additional capillary length scale for improved fluid wicking while preserving the micron-scale vapor escape locations available in traditional microstructured wicks. Nanostructured coatings provide pore radii on the order of a few tens of nanometer, at least two orders of magnitude less than the few tens of micron pore sizes prevalent in traditional porous surfaces, and hence provide high capillary pressures to overcome the viscous drag on fluid flow at the microscale and delay capillary dryout. Chen et al. [17] reported high CHF values $\left(\sim 200 \mathrm{~W} / \mathrm{cm}^{2}\right)$ and heat transfer coefficients $\left(\sim 6 \mathrm{~W} / \mathrm{cm}^{2} \mathrm{~K}\right)$ in pool boiling studies on flat silicon surfaces individually coated with dense arrays of Si nanowires fabricated by electro-less etching and $\mathrm{Cu}$ nanowires synthesized by electroplating of $\mathrm{Cu}$ into nanoporous alumina templates. The observed enhancement was attributed to superhydrophilicity and enhanced capillary pumping of the nanowire arrays. Yao et al. [18] investigated the effect of the height of $\mathrm{Cu}$ and $\mathrm{Si}$ nanowires fabricated by inexpensive electrochemical methods and observed that taller nanowire arrays enhanced pool boiling performance by providing stable active nucleation sites. Nam et al. [19] nanostructured copper micropost wicks by chemical oxidation to form $\mathrm{CuO}$ nanostructures. $\mathrm{CHF}$ values greater than $500 \mathrm{~W} / \mathrm{cm}^{2}$ were reported for a $2 \times 2 \mathrm{~mm}^{2}$ heat input area but decreased to $200 \mathrm{~W} / \mathrm{cm}^{2}$ in the case of a $5 \times 5 \mathrm{~mm}^{2}$ heat input area. Ding et al. [20] fabricated $3 \mathrm{~cm} \times 3 \mathrm{~cm} \times 600 \mu \mathrm{m}$ thick vapor chamber devices with hair-like nanostructured titania grown on Ti pillars, though only very low heat fluxes $\left(<10 \mathrm{~W} / \mathrm{cm}^{2}\right)$ were examined during thermal testing.

Complete coverage and patterning of wick surfaces with carbon nanotubes (CNTs) has found considerable interest in the research community $[14,15,21]$. CNTs are cylindrical nanostructures of graphitic carbon with outer diameters ranging from 1 to $100 \mathrm{~nm}$ and typical lengths from 1 to $50 \mu \mathrm{m}$. Apart from the benefits of nanostructuring discussed above, CNTs also possess high intrinsic thermal conductivity and a tunable porosity. Ujereh et al. [22] performed pool boiling experiments on CNTcoated silicon and copper substrates with distinct patterned areas of coverage and differing CNT array densities. Surfaces coated entirely with CNTs eliminated the large incipience superheat overshoot and the resulting substantial temperature drop upon incipience observed in the case of bare silicon and copper surfaces. CNT forests grown on silicon substrates [23] were reported to augment CHF values by $25 \%$ compared to bare silicon surfaces in addition to enhancing heat flux dissipated in the film boiling regime. Mechanisms proposed for this augmentation included increased surface areas for heat transfer provided 
by CNTs in the form of 'nanofins' and disruption and possible collapse of the vapor film in the film boiling regime resulting in improved transient quenching of the CNT surface compared to a bare silicon substrate. While these two studies utilized highly wetting dielectric fluids, water is the preferred working fluid for use in vapor chambers for electronics cooling applications. Pool boiling experiments on hybrid sintered/CNT surface [24] employing deionized water as the working fluid revealed a significant reduction in boiling incipience superheat compared to a plain flat copper surface.

It is essential to distinguish the heat transfer mechanisms encountered in pool boiling experiments from those seen in vapor chamber operation. In a vapor chamber, liquid migration to the heat input area occurs through capillary action in the wick structure and heat transfer occurs by evaporation at the liquid-vapor free interface at lower surface superheats and by boiling at the solid-liquid interface at higher surface superheats. In the case of pool boiling, the surface is completely submerged in liquid and heat is dissipated by natural convection until the surface temperature is high enough to initiate nucleate boiling. Therefore, any performance augmentation due to CNTs that were previously shown for pool boiling must be evaluated under capillary feeding conditions that exist in a vapor chamber.

The inherent hydrophobic nature of CNTs, however, limits their usage with water in vapor chambers. Several surface functionalization techniques for promoting CNT surface wetting behavior have been explored. Cai and Chen [14] used a $2 \%$ hydrochloric acid-treatment process to improve the surface wettability of CNTs. Using this technique, a CNT biwick structure consisting of parallel CNT stripes 100 $\mu \mathrm{m}$ wide and $50 \mu \mathrm{m}$ apart was fabricated and heat dissipation capacities of up to $600 \mathrm{~W} / \mathrm{cm}^{2}$ were demonstrated. Hashimoto et al. [15] deposited CNTs on a $1.5 \mathrm{~mm}$ thick layer of sintered copper powder by thermal chemical vapor deposition (CVD) and rendered them hydrophilic via exposure to ultraviolet (UV) radiation. Experiments were conducted to demonstrate that CNT-coated wicks removed heat fluxes up to $500 \mathrm{~W} / \mathrm{cm}^{2}$ at a superheat of $\sim 33{ }^{\circ} \mathrm{C}$, compared to a baseline sample without CNT-coating at a superheat of $\sim 45{ }^{\circ} \mathrm{C}$ at the same heat flux. The prevailing hypothesis to explain the surface wettability switch of CNTs in response to UV light exposure is based on the assisted adsorption of hydrophilic hydroxyl groups [25]. This method could conceivably minimize the surface degradation of CNTs compared to acid treatment processes, and potentially facilitate scalability. Nevertheless, this methodology is not expected to be feasible for continuous operation in thin vapor chambers due to likely degradation of surface wettability of UV-exposed CNT-coated wicks over time. The hydrophilic behavior of CNTs conformally coated with copper was previously demonstrated by our group [16, 21]. This method is advantageous for use in vapor chambers due to long-term compatibility of the copper coating with water. 
In recent work [16], the thermal characteristics of $1 \mathrm{~mm}$ thick monolithic and patterned sintered copper powder wicks were evaluated with and without a functionalized CNT coating. Patterning of the wick structure with a grid of square recesses reaching down to the substrate provided a low resistance vapor exit path to improve performance during vigorous boiling. Growth of a CNT array directly on the substrate in the patterned recesses in the wick structure did not provide any enhancement as they remained flooded during testing. A similar study was then conducted with $200 \mu \mathrm{m}$ thick sintered powder layers only a few particle layers deep and compatible for use in ultra-thin vapor chambers [26]. The intention was to compare the heat transfer enhancement mechanisms for the different wick layer thicknesses. While patterned samples without CNT coating reduced the dryout heat flux due to capillary fluid starvation over the surface, a CNT array grown in the patterned recesses resulted in active wicking of the fluid and increased the dryout heat flux. However, this study revealed that for $200 \mu \mathrm{m}$ thick wicks, monolithic samples generally outperformed grid-patterned samples due to the increase in the available liquid feeding area. In all test cases in the above studies [16, 26], CNT-coated wick structures were shown to reduce the superheat at boiling incipience, motivating a detailed study of boiling incipience for CNTcoated monolithic wicks [26]. In this study, a functionalized CNT coating was shown to reduce the mean surface superheat at the boiling incipience point by $5.6{ }^{\circ} \mathrm{C}$ compared to monolithic samples.

In the present work, we explore means of increasing the dryout heat flux of nanostructured monolithic wicks to accommodate the ever-increasing thermal loads of high-performance power electronics, while preserving the reduction in the boiling incipience superheat achieved in the previous work. We evaluate $200 \mu \mathrm{m}$ thick nanostructured wicks with different nominal thicknesses of the copper coating deposited on the CNTs, and compare their thermal and surface wetting characteristics with a bare sintered powder sample (without CNTs).

\section{Sample fabrication, experimental setup, and test procedure}

The sample fabrication process and the characterization procedure consistently employed for all the samples is described here in detail. The design of the experimental test facility used to simulate fluid transport in a vapor chamber and the test protocol for obtaining temperature and heat flux measurements are then described, followed by the experimental setup used to perform contact angle measurements on porous wick samples and the test procedure employed to ascertain the relative surface wettability between the samples. 


\subsection{Sample fabrication}

Four nominally identical sintered copper powder wick samples coated with CNTs are functionalized with varying nominal copper coating thickness of CNTs for assessing their relative thermal performance. The first sample is a bare sintered powder sample without CNTs and is used as a standard for comparison. The other three samples consist of CNT-coated wicks with 250, 500, and $750 \mathrm{~nm}$ of nominal copper coating thickness, respectively. The copper powder sintering, CNT synthesis, and hydrophilic functionalization procedures are maintained consistent for all the four samples.

\subsubsection{Sintered powder wick fabrication}

Similar to our previous work [26], the sintered powder samples consist of a $0.381 \mathrm{~mm}$ thick base solid substrate made of laminated $13 \%-74 \%-13 \%$ copper-molybdenum-copper $(\mathrm{Cu} / \mathrm{Mo} / \mathrm{Cu})$ sheets with a 200 $\mu \mathrm{m}$ thick top layer of sintered copper powder functioning as the wick structure. Copper particles of 100 $\mu \mathrm{m}$ average diameter are used for all samples. The sintering process involves setting the copper powder into a mold and exposing it to a high-temperature forming gas environment. The resulting structure has a volumetric porosity of approximately $50 \%$. The top sintered layer blankets the central $20.3 \mathrm{~mm} \times 20.3$ $\mathrm{mm}$ of the $25.4 \mathrm{~mm} \times 25.4 \mathrm{~mm}$ solid substrate, leaving adequate flat edges for sealing to the experimental chamber wall. All the samples used in this work are fabricated by Thermacore, Inc.

\subsubsection{Carbon nanotube synthesis and functionalization}

CNT synthesis and functionalization consists of three major processing steps, namely catalyst metal deposition, CNT growth by microwave plasma chemical vapor deposition (MPCVD), and physical vapor deposition of copper to functionalize the CNTs. The samples received from Thermacore, Inc., are subjected to a cleaning procedure involving acetone and isopropanol to remove any potential contamination or organic residues. A tri-layer catalyst stack of $30 \mathrm{~nm} \mathrm{Ti}, 7.5 \mathrm{~nm} \mathrm{Al}$, and $5 \mathrm{~nm} \mathrm{Fe}$ thick layers is deposited, in this order, on the central wick structure using a Varian electron beam physical vapor deposition system. The deposition rates of Ti, $\mathrm{Al}$, and Fe catalyst layers are $2 \AA / \mathrm{s}, 1.5 \AA / \mathrm{s}$, and 0.8 $\AA / s$, respectively. The Ti layer improves anchoring of the CNTs to the sintered powder/substrate, while the Al surfactant layer prevents the agglomeration of Fe nanocatalyst particles during CNT growth. The Fe layer provides nucleation and active catalytic growth sites for the CNTs. Multi-walled CNTs are grown on the catalyzed samples in a SEKI AX5200s MPCVD system. A detailed description of the CNT growth procedure is provided in [27]. In brief, the sample is placed in the chamber and vacuum pumps reduce the system pressure to $266 \mathrm{~Pa}$ ( $\sim 2$ Torr). The catalyzed sample is then annealed at $900{ }^{\circ} \mathrm{C}$ under 10 Torr of $\mathrm{N}_{2}$ to create Fe nanocatalyst particles on the surface. CNTs are grown for 10 minutes under a 300 
W plasma power with $50 \mathrm{sccm}$ of $\mathrm{H}_{2}$ and $10 \mathrm{sccm}$ of $\mathrm{CH}_{4}$. The system is then allowed to cool and the sample is removed.

CNT functionalization is carried out using a physical vapor deposition process. The three CNT-coated samples are functionalized with $250 \mathrm{~nm}, 500 \mathrm{~nm}$, and $750 \mathrm{~nm}$ nominal thicknesses of copper coating, respectively. It is important to note that nominal thickness is the thickness recorded by the crystal monitor, defined as the layer thickness deposited on a flat plate, and is not the actual thickness of the copper coating on the nanotubes. Typical values of actual copper coating thickness of CNTs corresponding to the nominal coating thickness recorded by the crystal monitor are discussed in section 2.1.3. The relatively lower binding energy of the copper atom on the CNT surface (0.10-0.14 eV/atom [28]), compared to other transition metals, promotes diffusion and collision of copper adatoms, leading to their agglomeration. When high deposition rates are used, the latent energy released by the condensing atom can give rise to appreciable substrate heating. A higher substrate temperature further enhances agglomeration of copper adatoms and can eventually lead to a non-uniform copper coating on the surface of the CNTs. In order to minimize non-uniformities in the copper coating, the deposition rates are maintained at $\leq 3 \AA / s$ during the entire process. A lower deposition rate of $1 \AA / s$ is used for the first 25 $\mathrm{nm}$ of the copper coating and a slightly higher rate of $3 \AA / \mathrm{s}$ is used during the remainder of the vapor deposition process. Any minor surface oxidation which might occur during storage is removed by subjecting the CNT-functionalized samples to a $300 \mathrm{~W}$ hydrogen plasma in the MPCVD chamber for 10 minutes with the substrate temperature at $100{ }^{\circ} \mathrm{C}$ prior to thermal testing. Digital images of the uncoated baseline sample (Fig.2 (a)) and the three CNT-coated samples (Fig.2 (b)-(d)) after the hydrogen plasma reduction procedure are shown in Fig. 2.

\subsubsection{Sample characterization}

Low- and high-magnification scanning electron microscopy (SEM) images of the multi-walled CNTs grown on the three samples with varying copper coating thickness are obtained using a Hitachi S-4800 field emission microscope and are presented in Fig. 3. As opposed to flat substrates, where vertically aligned CNT growth is obtained for similar growth conditions, the three-dimensional surface curvature of the sintered copper powder gives rise to randomly oriented meshes of CNTs of non-uniform height ranging between 1-10 $\mu \mathrm{m}$. A characterization study was carried out to compare the penetration depth of the coated copper on the moderate-density, randomly oriented CNTs grown on sintered copper powder versus that on high-density, vertically-aligned CNTs grown on a flat copper substrate. As shown in Fig. 4 (a), in the case of vertically aligned CNTs coated with a $250 \mathrm{~nm}$ nominal copper coating thickness, the penetration depth into the $20-35 \mu \mathrm{m}$ long CNTs is less than $5 \%$ of the total length. 
The random orientation, shorter length, and moderate density of CNTs grown on sintered wick structures, on the other hand, proved to be beneficial in obtaining a conformal copper coating along the entire length of the CNTs. SEM images (Fig. 3) of the three CNT-coated samples reveal that the entire exposed surface area of the CNTs is conformally coated with the evaporated copper, thereby promoting surface wettability and interstitial wicking of liquid. High-magnification SEM images of the three samples also expose a clear trend with respect to copper coating thickness. An increase in the nominal copper coating thickness resulted in larger effective diameters of the functionalized CNTs, in agreement with intuitive volumetric conservation. A quantitative estimate of the overall CNT diameter distribution for the randomly oriented CNTs is not attempted since automated image processing techniques typically employed for such estimation lack acceptable accuracy. The diameters of CNTs shown in Fig. 3 (b2)-(d2) are determined from manual image processing to be $85 \mathrm{~nm}, 154 \mathrm{~nm}$ and $275 \mathrm{~nm}$ corresponding to 250,500 and $750 \mathrm{~nm}$ samples respectively. Based on similar images of nanotubes obtained across the surfaces, these diameters are fairly representative. Although these numbers do not represent the entire range of CNT diameters for the three samples, they show that the functionalized CNT diameters can increase by at least a factor of three from the $250 \mathrm{~nm}$ to $750 \mathrm{~nm}$ nominal copper coating thickness samples. To enhance readability and avoid repetition, the CNT-samples coated with 250, 500, and $750 \mathrm{~nm}$ of nominal copper coating thickness will be henceforth referred to as the $250 \mathrm{~nm}, 500 \mathrm{~nm}$ and $750 \mathrm{~nm}$ samples, respectively.

\subsection{Test facility and procedure for thermal metrology}

The experimental setup, designed to mimic the internal conditions of a vapor chamber, is equipped to measure the substrate temperature of the wick structure when subjected to different heat fluxes as deionized water is supplied by capillary action. A detailed description of the experimental facility can be found in [8]. The experimental facility and procedure is described in brief here. Fig. 5 (a) shows a diagram of the experimental test chamber along with the heater block assembly. The test chamber is built from insulating PEEK and polycarbonate walls, which enclose a liquid bath with the surface level fixed precisely $8.25 \mathrm{~mm}$ beneath the heated area of the wick surface. During operation, as water evaporates from the wick surface, it is replenished by capillary-feeding from the bath. The vapor space and the liquid water bath are maintained at saturation temperature $\left(100{ }^{\circ} \mathrm{C}\right)$ and at atmospheric pressure as monitored via internal thermocouples and a pressure transducer.

In situ flow visualization of the wick surface is made possible using a Photron Fastcam-X 1024 PCI highspeed camera attached to a rigid borescope that is inserted into the test chamber through a seal in the wall. The camera records video at up to 10,000 frames per second and can be used to view normally and at a 45 
deg angle to the wick surface, permitting clear distinction of vapor formation regimes (i.e., evaporation versus boiling).

The heater block assembly (Fig. 5 (b)), enclosed in a ceramic insulating shell, is designed to supply a high heat flux input to the back of the wick substrate. The test sample is soldered to a copper heater block (heat source area of $5 \mathrm{~mm} \times 5 \mathrm{~mm}$ ) with a $0.102 \mathrm{~mm}$ thick Pb-Sn solder joint (conductivity $k_{s}=50 \mathrm{~W} / \mathrm{mK}$ ) in a specially designed graphite stand with a recessed pocket to hold the sample [8]. An inert argon gas environment is maintained throughout the soldering process to prevent potential surface oxidation at $200{ }^{\circ} \mathrm{C}$. The high thermal conductivity and precise thickness of the solder is essential to minimize the uncertainty in thermal resistance across the interface, especially at high heat fluxes. The copper heater block and sample assembly is sealed vertically against the test chamber (Fig. 5 (a)).

As mentioned in section 2.1.2, all samples are exposed to a hydrogen plasma in the MPCVD chamber prior to thermal testing. Additionally, the same test protocols are employed as in [16], permitting one-toone comparison against previous results. The test procedure begins by boiling water in the chamber vigorously in order to purge all non-condensable gases and produce a saturated water vapor environment. Each sample is subjected during testing to a series of increasing heat fluxes. For each test point, an electrical input is supplied to the embedded cartridge heaters and the system temperatures are allowed to stabilize. Steady state is defined by a variation in the substrate temperature of less than $0.1{ }^{\circ} \mathrm{C} / \mathrm{min}$ being achieved for a period of 10 minutes. The high-speed camera is used to record the corresponding evaporation or boiling process for each heat flux test point following acquisition of the steady state temperature data. This ensures that the reference thermocouple in the vapor space is not inadvertently heated to yield spurious temperature readings due to the high-intensity lighting.

Test results are reported in the form of a boiling curve. Each heat flux versus temperature point is generated from time-averaging 5 minutes of steady-state data. The measured linear temperature drop along a rake of thermocouples ( $T_{1}$ to $T_{4}$ ) embedded along the centerline of the copper heater block determines the heat flux $q^{\prime \prime}$ according to Fourier's law for one-dimensional heat flow. This calculation methodology allows a determination of the actual heat flux, and accounts for heat losses through the heater block insulation. The substrate temperature $T_{\text {substrate }}$ is found by extrapolating the measured temperature gradient to the substrate and accounting for the temperature drop across the solder joint according to

$T_{\text {substrate }}=T_{4}-q^{\prime \prime}\left[\frac{\left(x_{5}-x_{4}\right)}{k_{C u}}+\frac{t_{s}}{k_{s}}\right]$ 
where the copper conductivity $k_{C u}$ is taken as $400 \mathrm{~W} / \mathrm{mK}$. An uncertainty analysis is used to predict the uncertainties in heat flux and substrate temperature by propagating the error due to the following quantities: $\pm 0.3{ }^{\circ} \mathrm{C}$ in $T, \pm 0.08 \mathrm{~mm}$ in $x, \pm 25 \%$ in $t_{s}, \pm 5 \%$ in $k_{s}$, and $\pm 1 \times 10^{-4} \mathrm{~mm}^{2}$ in $A_{c}$.

\subsection{Test facility and procedure for surface wettability measurements}

The liquid-surface contact angle is a critical property that governs the capillary pressure supplied by a liquid meniscus in a porous structure. A lowered contact angle can increase the supplied capillary pressure substantially, thereby extending the capillary limit. For an impermeable surface, macroscopic static contact angles measured by placing a sessile droplet onto the surface provide a quantitative measure of the surface wettability. In the case of porous structures, since the wetting liquid droplets infiltrate the micro- and nano-scale pores, analogous measurement of a static contact angle is not possible. Hence, measurement of transient macroscopic contact angles that vary as a droplet infiltrates the porous surface (referred to as the dynamic contact angle) is employed for surface wetting characterization of porous wick structures.

A schematic diagram of the experimental setup used to record droplet infiltration into the wick surface is shown in Fig. 6 (a). A corresponding photograph of the experimental facility is provided in Fig. 6 (b). Contact angle experiments are conducted using a Ramé-Hart digital goniometer model 290 equipped with an automatic droplet dispensing system. A Jensen Global 32 gage HPX stainless steel needle is used for dispensing sessile deionized water droplets. The needle is attached to the automatic droplet dispensing system that allows for precise control over the volume and flow rate of droplet deposition on the porous surface using the DROPimage software. The small diameter of the needle also allows for a minimal droplet volume of $4.5 \mu \mathrm{l}$ to fall onto the surface under gravity. Videos are recorded at a speed of 2000 frames per second with a Photron Fastcam-X 1024 PCI high-speed camera. The camera lens provides a magnification of $0.01 \mathrm{~mm} /$ pixel over a $512 \times 512$ pixel image. A high-intensity Sunoptics Surgical Titan $300 \mathrm{~W}$ xenon light source is used to provide sufficient contrast between the liquid droplet and the air during imaging.

The procedure adopted for performing dynamic contact angle measurements is as follows. All the measurements are performed at room temperature and standard atmospheric pressure. The surface of the tilt stage is initially leveled with the help of tilt adjustment knobs and a spirit level. The sample is then placed on the tilt stage between the glass slides. The glass slides, affixed to the tilt stage, serve as alignment markers and ensure repeatable placement of the sample at the same location between trials. Each contact angle measurement trial involves automatic dispensing of a single $4.5 \mu$ deionized water 
droplet from a syringe pump while simultaneously recording video of the droplet infiltration into the porous wick sample. After each trial, the wick surface is thoroughly dried with a high pressure nitrogen gun to remove any absorbed water which might affect subsequent measurements. While performing the droplet deposition experiments, it is essential to maintain low Weber numbers to ensure rapid momentum dissipation and to prevent any splashing. Yarin [29] reviewed droplet impact dynamics on various surfaces and referred the initial droplet impact as a deposition regime. Gunjal et al. [30] placed water droplets on glass surfaces and noted that this regime occurred for Weber numbers less than 3, but referred to it as an oscillation regime due to the inherent ripples caused by the impact of the droplet with the surface. Clarke et al. [31] confirmed that, for porous surfaces, no splashing would occur for a We less than 1 , but oscillations are ever-present despite the dominance of capillary forces. The three stages of droplet infiltration proposed by Hilpert and Ben-David [32] also assume that the droplet impacts the surface with a low Weber number such that no rebound or splashing will occur. In the current study, a dispensed droplet volume of $4.5 \mu \mathrm{l}$ resulted in a pinch-off droplet diameter of $2 \mathrm{~mm}$ and a measured deposition velocity of $0.08 \mathrm{~m} / \mathrm{s}$, resulting in a Weber number of 0.175 . For this Weber number, the observed droplet impact is in the deposition regime, but moderate interface oscillations are still observed.

\section{Results and discussion}

\subsection{Capillary-fed evaporation and boiling results}

Quantitative and qualitative results for the capillary-fed boiling experiments conducted in a heat fluxcontrolled mode are presented. Experiments cease when a large temperature rise associated with the total dryout of the wick is observed. The heat flux (from a $5 \mathrm{~mm} \times 5 \mathrm{~mm}$ heat input area) versus substrate superheat temperature for all the four samples is plotted in Fig. 7. Finer increments of heat flux are used in the evaporation regime to capture the transition to boiling. To enhance readability of data for heat fluxes less than $90 \mathrm{~W} / \mathrm{cm}^{2}$, a zoomed version of the graph is depicted in the inset. Uncertainty values of \pm $0.5^{\circ} \mathrm{C}$ and $\pm 5 \mathrm{~W} / \mathrm{cm}^{2}$ on the abscissa and the ordinate are omitted. Maximum uncertainties of heat flux and substrate superheat are $5.1 \mathrm{~W} / \mathrm{cm}^{2}$ and $3.0^{\circ} \mathrm{C}$ respectively.

\subsubsection{Effect of varying CNT copper coating thickness on overall thermal performance}

The boiling curve for the bare sintered copper powder sample without CNTs shows three distinct regimes consistent with our observations in a recent study [26]. At low heat fluxes $\left(<50 \mathrm{~W} / \mathrm{cm}^{2}\right)$, the substrate superheat is relatively low and heat transfer occurs by thin-film evaporation from the liquid-vapor interface at the top sintered particle layer. At moderately high heat fluxes (between 50 and $350 \mathrm{~W} / \mathrm{cm}^{2}$ ), heat transfer is dominated by boiling at the substrate-wick interface and capillary pressure generated in the pores of the wick continue to assist liquid flow to the central heated portion. Between these regimes, 
an abrupt transition to boiling occurs at a surface superheat of $7.9^{\circ} \mathrm{C}$, and results in a noticeable drop in substrate temperature. Boiling incipience is also characterized by a sharp reduction in the evaporator thermal resistance, as shown in Fig. 8. The evaporator thermal resistance is defined as

$$
R_{\text {sample }}=\frac{\left(T_{\text {substrate }}-T_{\text {ref }}\right)}{q^{\prime \prime} A_{c}}
$$

As opposed to the evaporation regime where conduction through the wick adds to the overall thermal resistance from the substrate to the vapor, the wick conduction resistance is bypassed under boiling conditions leading to an overall reduction in thermal resistance [8]. Beyond a heat flux input of 350 $\mathrm{W} / \mathrm{cm}^{2}$, a partial dryout is observed in the central region of the wick leading to a reduced heat transfer coefficient, evident from the reduced slope of the boiling curve. This performance degradation trend continues until total dryout is observed. In this study, the last heat flux test point for which steady-state conditions are reached is designated as the dryout heat flux. A qualitative comparison of the estimated dryout heat flux for all the samples is provided in a later subsection. In the case of the bare baseline sample, the dryout heat flux is found to be $437 \mathrm{~W} / \mathrm{cm}^{2}$ at a surface superheat of $23.3^{\circ} \mathrm{C}$. The dryout heat flux of this $200 \mu \mathrm{m}$ uncoated wick is lower than the value reported earlier for $1 \mathrm{~mm}$ thick wicks [16], consistent with the previously reported trends [12].

The $250 \mathrm{~nm}$ sample displays similar evaporation and boiling regimes as a bare sintered powder sample. The substrate superheats of the baseline and the $250 \mathrm{~nm}$ sample are also very similar and indistinguishable within experimental uncertainty throughout the boiling regime. Based on the thermal performance data and in situ visualization, the transition from the evaporation to boiling regime is found to occur at a lower surface superheat of $6.0{ }^{\circ} \mathrm{C}$ for the $250 \mathrm{~nm}$ copper coated CNT sample compared to the baseline sample. Although boiling incipience temperature is reduced, the dryout heat flux for the 250 $\mathrm{nm}$ sample is degraded, and occurs at $356 \mathrm{~W} / \mathrm{cm}^{2}$. CNT samples with $500 \mathrm{~nm}$ and $750 \mathrm{~nm}$ copper coating thickness also exhibit an earlier transition to the boiling regime, consistent with our previous results [26]. Incipience substrate superheat temperatures of $2.3{ }^{\circ} \mathrm{C}$ and $2.1^{\circ} \mathrm{C}$ are measured for the $500 \mathrm{~nm}$ and 750 nm samples, respectively, as opposed to $7.9^{\circ} \mathrm{C}$ and $6.0^{\circ} \mathrm{C}$ for the bare and $250 \mathrm{~nm}$ coated samples.

Apart from the reduction in boiling incipience superheat, another performance enhancement trend is discernible with increasing copper coating thickness; an increase in thickness improves the thermal performance in both the evaporation and boiling regimes. Comparison of thermal resistances of the four samples (Fig. 8) clearly shows that the samples with thicker copper coating (500 nm and $750 \mathrm{~nm}$ ) demonstrate lower overall resistances compared to the bare and $250 \mathrm{~nm}$ coated sample. The maximum reduction in thermal resistance, in the amount of $0.34{ }^{\circ} \mathrm{C} / \mathrm{W}$ compared to the bare sample, was achieved 
with the $750 \mathrm{~nm}$ sample at a heat flux of $\sim 20 \mathrm{~W} / \mathrm{cm}^{2}$. Compared to the $250 \mathrm{~nm}$ sample, the $500 \mathrm{~nm}$ and the $750 \mathrm{~nm}$ samples also show an increased dryout heat flux of approximately $457 \mathrm{~W} / \mathrm{cm}^{2}$ (corresponding to respective surface superheat temperatures of $20.9{ }^{\circ} \mathrm{C}$ and $13.9{ }^{\circ} \mathrm{C}$ ).

The propensity of CNTs to initiate bubble nucleation at lower surface superheats was previously reported in pool boiling studies $[22,24]$ as well as for CNT-enhanced wicks [16, 26]. It is notable that this phenomenon is independent of wick thickness for millimeter and sub-millimeter thick wicks.

\subsubsection{Effect of varying copper coating thickness on dryout heat flux}

The boiling performance plot (Fig. 7) and the flow visualization acquired through high-speed imaging can be used to estimate the dryout heat flux of the four samples. It is noted here that the capillary limit is the proposed mechanism for dryout for the wick structures considered in this study (justified by an analysis presented in a later section). Figure 9 compares the partial dryout area in the central heated region for the $250 \mathrm{~nm}, 500 \mathrm{~nm}$, and the $750 \mathrm{~nm}$ samples for corresponding final heat flux test points $\left(356 \mathrm{~W} / \mathrm{cm}^{2}, 457\right.$ $\mathrm{W} / \mathrm{cm}^{2}$ and $457 \mathrm{~W} / \mathrm{cm}^{2}$, respectively). These images are extracted from the flow visualization videos recorded with a high-speed camera at the same magnification. As a general trend, a consistently diminishing partial dryout area is observed with an increase in the copper coating thickness. It is clear that the partial dryout area for the $250 \mathrm{~nm}$ sample is larger even at a comparatively lower heat flux test point of $356 \mathrm{~W} / \mathrm{cm}^{2}$ than the other samples. This suggests that, at this heat flux test point, the fluid encountered significant pressure drop along the path due to the viscous drag forces preventing liquid replenishment leading to partial dryout of the central region. Therefore, even though the $250 \mathrm{~nm}$ sample is able to dissipate $356 \mathrm{~W} / \mathrm{cm}^{2}$ at approximately the same substrate temperature $\left(\sim 14{ }^{\circ} \mathrm{C}\right)$ as the $500 \mathrm{~nm}$ sample, the thinner copper-coating resulted in a structure not capable of generating adequate capillary pressure above this heat flux.

Both the $500 \mathrm{~nm}$ and the $750 \mathrm{~nm}$ samples effectively dissipate $457 \mathrm{~W} / \mathrm{cm}^{2}$ at the last test point prior to total dryout. However, the $750 \mathrm{~nm}$ sample is able to do so at a reduced superheat of $13.9{ }^{\circ} \mathrm{C}$ as opposed to $20.9^{\circ} \mathrm{C}$ for the $500 \mathrm{~nm}$ sample. This performance enhancement trend is supported by the smaller partial dryout area observed for the $750 \mathrm{~nm}$ sample at this heat flux (Fig. 9), commensurate with a lower surfaceaveraged thermal resistance. The relatively small dryout area and reduced operating temperature of the $750 \mathrm{~nm}$ sample at the final heat flux test point suggest that the maximum heat flux supported by the 750 $\mathrm{nm}$ sample is highest. Since the baseline bare sample dissipates a slightly reduced heat flux of $437 \mathrm{~W} / \mathrm{cm}^{2}$ at a relatively higher superheat of $23.9^{\circ} \mathrm{C}$, we may conclude that it has a comparatively lower dryout heat 
flux than the $500 \mathrm{~nm}$ and $750 \mathrm{~nm}$ samples. Based on the above discussion, the CNT-coated sample functionalized with $750 \mathrm{~nm}$ performs best.

The dryout heat flux of the best performing sample in the current study compares favorably to the corresponding values reported in the literature for thin wick structures (typically $<1 \mathrm{~mm}$ ). The CHF of sintered copper mesh wicks with thicknesses in the range $0.21-0.82 \mathrm{~mm}$ were reported to be as high as $368 \mathrm{~W} / \mathrm{cm}^{2}$ at a surface superheat of $23{ }^{\circ} \mathrm{C}$ [11]. Semenic and Catton [12] demonstrated maximum CHF (corresponding superheat) values of $300 \mathrm{~W} / \mathrm{cm}^{2}\left(21^{\circ} \mathrm{C}\right)$ and $520 \mathrm{~W} / \mathrm{cm}^{2}\left(50{ }^{\circ} \mathrm{C}\right)$ for the thin monoporous and biporous wicks, respectively. Zhao and Chen [13] showed a dryout heat flux of $350 \mathrm{~W} / \mathrm{cm}^{2}$ for a 3 $\mathrm{mm}$ thick wick with microgrooves. Our recent investigation of $1 \mathrm{~mm}$ sintered powder wicks [16] revealed a dryout heat flux of $514 \mathrm{~W} / \mathrm{cm}^{2}\left(46^{\circ} \mathrm{C}\right)$ for bare sintered wicks without patterning, while the corresponding value increased to $560 \mathrm{~W} / \mathrm{cm}^{2}\left(35^{\circ} \mathrm{C}\right.$ ) for grid-patterned sintered wicks. The $200 \mu \mathrm{m}$ thick sintered wicks evaluated in this study are compatible with sub-mm vapor chambers and show high CHF values $\left(457 \mathrm{~W} / \mathrm{cm}^{2}\right)$ at a reduced surface superheat of $13.9^{\circ} \mathrm{C}$.

\subsubsection{Mechanism of dryout}

We demonstrate here that the capillary limit is the mechanism for dryout of the wick structures investigated in this study. Dryout of a wick surface can occur either by the hydrodynamic instability mechanism originally proposed by Zuber [33], commonly referred to as the critical heat flux (CHF), or by a liquid replenishment mechanism (i.e., the capillary limit). The hydrodynamic instability limit is reached when the interfaces of the liquid-vapor counterflow columns become Helmholtz-unstable. Liter and Kaviany [34] demonstrated that the hydrodynamic limit can be significantly increased using modulated porous structures which provide preferential flow paths for liquid and vapor, thereby reducing the liquid/vapor counterflow situations and aiding non-hydrodynamical determination of the critical instability wavelength. Various other studies also report a significant increase in critical heat flux (CHF) of uniformly coated porous surfaces compared to plain surfaces investigated under natural convection boiling conditions $[17,35]$. Reasons for this reported enhancement include heat transfer from extended surfaces, an increase in nucleation site density, and enhanced lateral liquid replenishment to the active nucleation sites via capillary action that reduces the liquid-vapor counterflow resistance.

The hydrodynamic limit of a bare sintered powder sample without CNTs can be estimated using an extension of Zuber's theory suggested by Polezhaev and Kovalev [36] for porous surfaces. A similar analysis has been employed by others with satisfactory predictions [17, 34]. Using a volumetric porosity $\varepsilon$ of $0.5 \pm 0.02$, an average breakthrough bubble diameter $d_{b r}$ of $42 \mu \mathrm{m}$ (determined from the average pore 
diameter ), and thermophysical properties of water at saturation temperature $\left(100{ }^{\circ} \mathrm{C}\right)$, the hydrodynamic limit of the bare sample is estimated to be $906 \pm 102 \mathrm{~W} / \mathrm{cm}^{2}$ using:

$$
q_{C H F, \text { porous }}^{\prime \prime}=\frac{\pi}{24} \rho_{g}^{1 / 2} h_{f g}\left[\sigma g\left(\rho_{l}-\rho_{g}\right)\right]^{1 / 4} \frac{3\left[\sigma / g\left(\rho_{l}-\rho_{g}\right)\right]^{1 / 4}}{\lambda_{u}^{1 / 2}}
$$

where

$\lambda_{u}=\left(\frac{\pi}{5.88 \varepsilon^{2.28}}\right)^{2} d_{b r}$

This estimated value of the maximum heat flux constrained by hydrodynamical instabilities is much higher than the observed value of $437 \mathrm{~W} / \mathrm{cm}^{2}$ for the bare baseline sample. Thin porous layers such as the one employed here (wick thickness of $200 \mu \mathrm{m}$ ) exhibit relatively low resistance to vapor escape and can extend the hydrodynamic instability limit to large values. As long as the bubble nucleating at the wicksubstrate interface can easily escape from the wick structure and prevent the formation of an insulating vapor film, the hydrodynamic limit is not encountered. Equivalent arguments hold for nanostructured wick surfaces which also enhance lateral liquid replenishment due to high capillary pressures. Also, since the heat flux values reported in Fig. 7 are based on the $5 \mathrm{~mm} \times 5 \mathrm{~mm}$ input area, the actual heat flux encountered at the base of the wick structure is somewhat lower due to the spreading of heat in the $\mathrm{Cu}$ Mo-Cu substrate.

This analysis suggests that dryout of all the wick samples in this study was brought about, instead, by the capillary limit, also referred to as the liquid replenishment limit. A capillary limit is reached in a wick structure when the pressure drop due to viscous and gravitational forces exceeds the capillary pressure generated in the pores. As the heat flux is incremented, the liquid flow rate increases to compensate for the increased evaporative mass transport, which also results in higher viscous-drag resistance. Because of this effect, as the maximum dryout heat flux is approached, partial radial dryout of the surface begins in the central-most regions of the wick most readily deprived of liquid, and eventually leads to total dryout of the wick structure at high heat fluxes.

\subsubsection{Surface morphology after thermal testing}

A digital image of the $750 \mathrm{~nm}$ sample taken after thermal testing is presented in Fig. 10 (a). Based on the surface morphology characterization via the electron micrographs in Figs 10 (b) through (g), two distinct regions may be delineated on the wick structure: 1) the central $5 \mathrm{~mm}$ x $5 \mathrm{~mm}$ region over which the localized heat input was supplied (and subsequently dryout was observed) during thermal testing, and 2) the external region that aided the capillary pumping of the liquid to the central region. Fig. 10 (b) and Fig. 
10 (c), (d) show low- and high-magnification SEM images of the external regions of the wick structure, respectively. These images reveal no observable differences in the surface morphology of the micronsized sintered copper powder and the nano-porous CNTs before (Fig. 3) and after (Fig. 10) thermal testing. In certain areas of the external region (Fig. 10 (d)) however, Ostwald ripening of the copper coating on the CNTs (i.e., migration to and agglomeration at the CNT tips) is observed. Ostwald ripening is believed to occur at higher substrate temperatures because migration of the copper coating yields a surface energy minimum.

The images of the central dryout region reveal significant differences in surface morphology of the sintered powder following thermal testing. While the original sintered copper powder particles were 100 $\mu \mathrm{m}$ in average diameter, smaller particles on the order of tens of microns in diameter are formed on the larger particle surfaces following testing, as shown in Fig. 10 (e). In several regions of the exposed surface of the Cu-Mo-Cu substrate (Fig. 10 (f)) and the larger sintered particles (Fig. 10 (g)), cracking and degradation is observed. In addition, CNTs grown on the sintered powder in the dryout area are also found to have detached after testing. While it is difficult to ascertain the exact cause of this structural damage to the central region of the wick surface post-testing, it is believed to have occurred at or near the dryout heat flux test point. This theory is supported by prior capillary-fed [37] and pool boiling [24] investigations in which CNT-coated samples were evaluated below the dryout heat flux, and at least partial CNT coverage was observed to be retained post-testing. In future studies, thermal cycling tests at moderate heat fluxes will be performed to evaluate structural degradation of these wick samples over time.

\subsection{Dynamic contact angle measurements}

To ascertain and compare the surface wetting behavior of bare (no CNTs) and copper-functionalized CNT-coated porous wick surfaces and to demonstrate the enhanced surface wettability with thicker copper coatings, dynamic contact angle measurements are performed for the bare sintered powder, and the $250 \mathrm{~nm}$ and $750 \mathrm{~nm}$ coated samples.

Droplet infiltration into porous media has been investigated in prior studies. Denesuk [38] developed an analytical model for droplet suction into porous media, treating the individual pores as vertical cylinders into which liquid penetrates. The model was developed for two limiting cases - a fixed contact line with varying contact angle, and a fixed contact angle with varying contact area - but did not provide any insight into when these regimes might occur. Bacri and Brochard [39] observed similar pinned and unpinned contact line regimes by forcing a water-glycerol droplet into a porous membrane. Clarke et al. 
[31] extended this investigation to analyze the infiltration regimes of droplets falling onto porous surfaces with a low Weber number. Placement of water/glycerol/hexylene glycol droplets onto microporous filter membranes revealed three clear infiltration regimes as illustrated in Fig. 11:

(1) The droplet initially spreads over the surface and the contact angle slowly decreases until a macroscopic equilibrium advancing contact angle $\theta_{a}$ is reached and the contact line velocity $\mathrm{V}_{\mathrm{cl}}$ gradually tends to zero.

(2) The contact line remains fixed as the contact angle decreases until the macroscopic equilibrium receding contact angle $\theta_{r}$ is reached.

(3) The contact angle remains fixed at $\theta_{r}$ and the contact line recedes until the droplet is completely absorbed into the surface and disappears.

These three regimes were later referred to as stages of increasing drawing area (IDA), constant drawing area (CDA), and decreasing drawing area (DDA) by Hilpert and Ben-David [32], who developed a generalized analytical model that was in agreement with the experimentally measured infiltration behavior and could predict the conditions under which each regime would occur. The total time of the droplet infiltration is denoted by $\tau_{f}$. The contact angle of interest for the porous surface is bounded by the $\theta_{a}$ and $\theta_{r}$ values.

\subsubsection{Effect of varying copper coating thickness on surface wettability}

The samples used for these measurements, namely, the bare sample without CNTs, $250 \mathrm{~nm}$ coated, and $750 \mathrm{~nm}$ coated samples are nominally identical to the samples used for thermal testing and the same processing conditions were stringently adopted during sample fabrication (as described in section 2). To remove any minor surface oxidation, all the samples are treated with a $300 \mathrm{~W}$ hydrogen plasma for 10 minutes with the substrate temperature at $100^{\circ} \mathrm{C}$ in the same MPCVD system used for CNT synthesis. Fifteen measurement trials were performed on each sample on the exact same region of the wick surface with the aid of alignment markers. Despite the drying procedure employed, it was observed that following approximately the fifth successive trial, the sample wetting behavior changed and total time of droplet infiltration, $\tau_{\mathrm{f}}$, reduced with a further increase in the number of trials. Hence, only the initial trials with the same total droplet infiltration time are selected for exhaustive analysis. The results presented here correspond to trial numbers 3,4 , and 5 for each sample.

Representative stages of droplet infiltration are shown in Fig. 12. It is clear that oscillations are prevalent during the first few milliseconds of droplet impact. The inertial forces persist during the IDA phase and become weak during the later stages. As expected, the contact angle decreases as a function of time 
through IDA and CDA phases. The drawing radius can be seen to remain relatively constant in the CDA phase before complete droplet absorption occurs in the DDA phase.

Two separate algorithms were developed in-house using MATLAB's optimized Prewitt edge-detection algorithm and image processing toolbox to determine the dynamic contact angles and drawing radius of the droplets from the high-speed videos. It is noted that depending on the surface wetting behavior, the droplet infiltration process might start and end during any of the three phases. All the three phases (IDA, CDA and DDA) are observed using water with the three samples tested herein. During the later stages of droplet infiltration (at the end of the CDA phase and throughout the entire DDA phase), the contact angle and drawing radius determination becomes less accurate, and hence, the analysis is performed only while these parameters may be reliably obtained (typically until about halfway through the CDA phase). The mean drawing radius and contact angle, averaged over three trials, are extracted from the high-speed videos for each sample and are plotted as a function of time in Fig. 13.

As indicated in the figure, the left y-axis plots the drawing radius, while the contact angle is plotted on the right y-axis. The interface radius increases almost linearly with time for all three samples, with approximately the same slope until time $\tau=7.5 \mathrm{~ms}$. During the same time, the contact angles of all three samples decrease exponentially from an initial contact angle value of $\theta_{i} \approx 150^{\circ}$. This phase of droplet infiltration is denoted as the IDA phase. In the second stage of droplet infiltration, referred to as the CDA phase, the time-averaged drawing radius remains constant with minor oscillations due to inertial forces, while the contact angle continues to decrease exponentially. Since the CDA phase is relatively shorter for the $750 \mathrm{~nm}$ coated sample, fewer data points are available from the analysis for this sample. The equilibrium advancing contact angle $\theta_{a}$ for each sample is calculated as the contact angle at the intersection of the IDA and the CDA phase based on the fitted exponential curve. While a higher $\theta_{a}$ value of $\sim 44^{\circ}$ is extracted for the bare and the $250 \mathrm{~nm}$ coated sample, the $750 \mathrm{~nm}$ coated sample exhibits a $\theta_{a}$ value of $\sim 35^{\circ}$.

The procedure described above allows for prediction of the equilibrium advancing contact angle $\theta_{a}$, which is the upper bound for the equilibrium liquid-solid static contact angle. The equilibrium receding contact angle $\theta_{r}$ is not ascertained due to the extremely low contact angles observed. However, $\theta_{r}$ can be qualitatively inferred from the total droplet infiltration time based on the analytical results obtained in [32]. Physically, a shorter infiltration time at constant wick permeability is a consequence of an increased capillary pressure, which is dependent on the contact angle. Assuming an equilibrium static contact angle $\theta$ bounded by $\theta_{a}$ and $\theta_{r}$ is used for predicting capillary pressure of the wick structure, lowering either of 
these values promotes capillarity and consequently reduces $\tau_{f}$. A comparison of the $\tau_{f}$ values for the three samples is obtained from high-speed imaging and is tabulated as an inset in Fig. 13. These values reveal that the total droplet infiltration time of $29.5 \mathrm{~ms}$ for the $750 \mathrm{~nm}$ sample is the lowest of the three samples. Since the $\theta_{a}$ value for the $750 \mathrm{~nm}$ sample obtained from the preceding experiments is also lower in comparison to the other two samples, it clearly indicates that the thickest coating considered here yields the highest capillarity and likely the lowest equilibrium receding contact angle $\theta_{r}$ among the three samples. Based on the same argument, when $\theta_{a}$ values of two porous surfaces are alike, the surface with a shorter droplet penetration time will correspond to a lower $\theta_{r}$, provided the permeability is held constant. Hilpert and Ben-David [32] draw a similar conclusion from their analytical model. This argument may be employed to find relative $\theta_{r}$ values for the bare and $250 \mathrm{~nm}$ samples. Based on a shorter infiltration time (67.5 ms) for the bare sample compared to the $250 \mathrm{~nm}$ sample (with the largest $\tau_{f}$ of $117 \mathrm{~ms}$ ), it is concluded that the $\theta_{r}$ is lower for the bare sample. To summarize the results from this section, $\left(\theta_{a}, \theta_{r}\right)_{750 \mathrm{~nm}}$ $<\left(\theta_{a}, \theta_{r}\right)_{\text {bare }} \leq\left(\theta_{a}, \theta_{r}\right)_{250 \mathrm{~nm}}$.

\subsubsection{Implications of enhanced surface wettability on the estimated dryout heat flux}

In section 3.1.2, the dryout heat flux of the samples was qualitatively estimated and it was concluded that

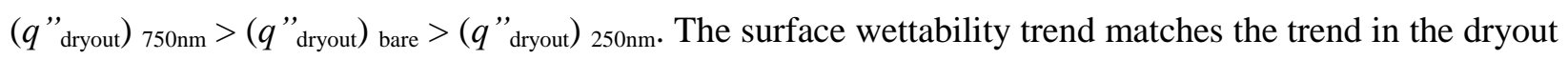
heat flux, as would be expected for a capillary-limited dryout phenomenon. It should be noted that the contact angles reported in the prior section are measured at room temperature. The contact angles at higher liquid temperatures $\left(\approx 100{ }^{\circ} \mathrm{C}\right)$ encountered during boiling would differ from the reported values due to temperature-dependence. The temperature dependence of contact angle on polished and roughened (but not porous) surfaces has been reported in [40,41], wherein the authors observe constant contact angles in the low temperature regime (typically less than $100^{\circ} \mathrm{C}$ ) and a linearly decreasing trend for higher temperatures. Based on these results from the literature, the actual contact angles during thermal testing are expected to be lower than the values reported here for room temperature; however, we expect no changes in the trend of changes in surface wettability for the samples. Hence, given liquid replenishmentlimited conditions, the $750 \mathrm{~nm}$ sample with the lowest predicted contact angle is concluded to most effectively feed liquid to the wick region which explains the observed maximum heat flux dissipation for this sample among the samples tested. The copper coating on the CNTs functions very well as a hydrophilic coating and could be potentially exploited for other applications requiring enhanced surface wetting.

Although nominal copper coating thicknesses larger than $750 \mathrm{~nm}$ were not experimentally investigated in this study, we expect that the improved thermal performance brought forth by improved surface 
wettability and higher capillary pressures will eventually be neutralized, as the coating thickness is increased further, by a decrease in flow permeability. This trade-off is expected to lead to an optimum copper coating thickness for achieving overall thermal performance enhancement.

\section{Conclusions}

Sintered copper powder wicks of $200 \mu \mathrm{m}$ thickness, nanostructured with carbon nanotubes rendered hydrophilic with different thicknesses of a copper coating, are examined as a means to achieve enhanced thermal performance and dissipate higher heat fluxes in vapor chambers. Thermal performance tests are undertaken using a capillary-fed boiling test facility designed to simulate a vapor chamber environment. Surface wetting characterization of the samples is carried out with a goniometer test setup equipped with high-speed imaging capability to capture the infiltration of water droplets into the porous surface. The resulting surface wettability trends are compared to the thermal performance trends for different copper coating thicknesses on the CNTs, and the mechanisms of enhancement are revealed. The key conclusions are summarized as follows:

(1) An increase in the copper coating thickness, indicated by larger effective coated carbon nanotube diameters, enhances capillary action resulting from the creation of hydrophilic nanoscale pores and overall increased wettability of the porous structure.

(2) Thermal performance tests reveal reduced boiling incipience superheat temperatures, enhanced heat transfer coefficients, and lower overall thermal resistance for the CNT-coated wicks with the thicker copper coatings.

(3) Higher dryout heat fluxes are supported by the thicker copper coatings on the CNTs. The estimated capillary dryout heat flux trend is substantiated by dynamic contact angle measurements performed to ascertain the relative surface wettability.

\section{Acknowledgements}

Financial support for this work provided by the Defense Advanced Research Projects Agency (DARPA) and Space and Naval Warfare Systems Center (SPAWAR/SYSCEN) San Diego, CA under Contract No. N66001-08-C-2011 is greatly appreciated. Special thanks are extended to Mark T. North of Thermacore Incorporated for fabrication and supply of the sintered copper power samples.

\section{References}

[1] J.-M. Koo, S. Im, L. Jiang, K.E. Goodson, Integrated microchannel cooling for three-dimensional electronic circuit architectures, Journal of Heat Transfer, 127(1) (2005) 49-58.

[2] S.V. Garimella, V. Singhal, D. Liu, On-chip thermal management with microchannel heat sinks and integrated micropumps, Proceedings of the IEEE, 94(8) (2006) 1534-1548. 
[3] T. Harirchian, S.V. Garimella, Boiling heat transfer and flow regimes in microchannels - a comprehensive understanding, Journal of Electronic Packaging, 133(1) (2011) 011001-011010.

[4] D.C. Wadsworth, I. Mudawar, Enhancement of single-phase heat-transfer and critical heat-flux from an ultrahigh-flux simulated microelectronic heat-source to a rectangular impinging jet of dielectric liquid, Journal of Heat Transfer-Transactions of the ASME, 114(3) (1992) 764-768.

[5] C.-Y. Li, S.V. Garimella, Prandtl-number effects and generalized correlations for confined and submerged jet impingement, International Journal of Heat and Mass Transfer, 44(18) (2001) 3471-3480.

[6] L.C. Lin, R. Ponnappan, Heat transfer characteristics of spray cooling in a closed loop, International Journal of Heat and Mass Transfer, 46(20) (2003) 3737-3746.

[7] S.V. Garimella, Y.K. Joshi, A. Bar-Cohen, R. Mahajan, K.C. Toh, V.P. Carey, M. Baelmans, J. Lohan, B. Sammakia, F. Andros, Thermal challenges in next generation electronic systems - summary of panel presentations and discussions, IEEE Transactions on Components and Packaging Technologies, 25(4) (2002) 569-575.

[8] J.A. Weibel, S.V. Garimella, M.T. North, Characterization of evaporation and boiling from sintered powder wicks fed by capillary action, International Journal of Heat and Mass Transfer, 53(19-20) (2010) 4204-4215.

[9] S.G. Kandlikar, A.V. Bapat, Evaluation of jet impingement, spray and microchannel chip cooling options for high heat flux removal, Heat Transfer Engineering, 28(11) (2007) 911-923.

[10] C. Li, G.P. Peterson, Evaporation/boiling in thin capillary wicks (ii) - effects of volumetric porosity and mesh size, Journal of Heat Transfer, 128(12) (2006) 1320-1328.

[11] C. Li, G.P. Peterson, Y.X. Wang, Evaporation/boiling in thin capillary wicks (i) - wick thickness effects, Journal of Heat Transfer, 128(12) (2006) 1312-1319.

[12] T. Semenic, I. Catton, Experimental study of biporous wicks for high heat flux applications, International Journal of Heat and Mass Transfer, 52(21-22) (2009) 5113-5121.

[13] Y. Zhao, C.-L. Chen, An investigation of evaporation heat transfer in sintered copper wicks with microgrooves, in: ASME 2006 International Mechanical Engineering Congress and Exposition (IMECE2006), Chicago, IL, USA 2006, pp. 177-181.

[14] Q. Cai, C.-L. Chen, Design and test of carbon nanotube biwick structure for high-heat-flux phase change heat transfer, Journal of Heat Transfer, 132(5) (2010) 052403-052408.

[15] M. Hashimoto, H. Kasai, Y. Ishida, H. Ryoson, K. Yazawa, J.A. Weibel, S.V. Garimella, A two-phase heat spreader for cooling high heat flux sources, in: 12th IEEE Intersociety Conference on Thermal and Thermomechanical Phenomena in Electronic Systems (ITherm), Las Vegas, NV, USA, 2010, pp. 1-8.

[16] J.A. Weibel, S.S. Kim, T.S. Fisher, S.V. Garimella, Carbon nanotube coatings for enhanced capillary-fed boiling from porous microstructures, Nanoscale and Microscale Thermophysical Engineering, 16(1) (2012) 1-17.

[17] R. Chen, M.C. Lu, V. Srinivasan, Z. Wang, H.H. Cho, A. Majumdar, Nanowires for enhanced boiling heat transfer, Nano Letters, 9(2) (2009) 548-553.

[18] Z. Yao, Y.W. Lu, S.G. Kandlikar, Effects of nanowire height on pool boiling performance of water on silicon chips, International Journal of Thermal Sciences, 50(11) (2011) 2084-2090.

[19] Y. Nam, S. Sharratt, G. Cha, Y.S. Ju, Characterization and modeling of the heat transfer performance of nanostructured cu micropost wicks, Journal of Heat Transfer, 133(10) (2011) 101502-101507.

[20] D. Changsong, G. Soni, P. Bozorgi, B.D. Piorek, C.D. Meinhart, N.C. MacDonald, A flat heat pipe architecture based on nanostructured titania, Journal of Microelectromechanical Systems, 19(4) (2010) 878-884.

[21] S.S. Kim, J.A. Weibel, T.S. Fisher, S.V. Garimella, Thermal performance of carbon nanotube enhanced vapor chamber wicks, in: 14th International Heat Transfer Conference (IHTC14) Washington, DC, USA 2010, pp. $417-$ 424.

[22] S. Ujereh, T.S. Fisher, I. Mudawar, Effects of carbon nanotube arrays on nucleate pool boiling, International Journal of Heat and Mass Transfer, 50(19-20) (2007) 4023-4038.

[23] H.S. Ahn, N. Sinha, M. Zhang, D. Banerjee, S. Fang, R.H. Baughman, Pool boiling experiments on multiwalled carbon nanotube forests, Journal of Heat Transfer, 128(12) (2006) 1335-1342.

[24] J.P. McHale, S.V. Garimella, T.S. Fisher, G.A. Powell, Pool boiling performance comparison of smooth and sintered copper surfaces with and without carbon nanotubes, Nanoscale and Microscale Thermophysical Engineering, 15(3) (2011) 133-150.

[25] A.S. Kousalya, C.N. Hunter, S.A. Putnam, T. Miller, T.S. Fisher, Photonically enhanced flow boiling in a channel coated with carbon nanotubes, Applied Physics Letters, 100(7) (2012) 071601-071604.

[26] J.A. Weibel, A.S. Kousalya, T.S. Fisher, S.V. Garimella, Characterization and nanostructured enhancement of boiling incipience in capillary-fed, ultra-thin sintered powder wicks, in: The 13th Intersociety Conference on Thermal and Thermomechanical Phenomenon in Electronic Systems, San Diego, CA, USA, 2012. 
[27] J. Xu, T.S. Fisher, Enhancement of thermal interface materials with carbon nanotube arrays, International Journal of Heat and Mass Transfer, 49(9-10) (2006) 1658-1666.

[28] H.J. Hwang, O.-K. Kwon, J.W. Kang, Copper nanocluster diffusion in carbon nanotube, Solid State Communications, 129(11) (2004) 687-690.

[29] A.L. Yarin, Drop impact dynamics: Splashing, spreading, receding, bouncing, Annual Review of Fluid Mechanics, 38(1) (2006) 159-192.

[30] P.R. Gunjal, V.V. Ranade, R.V. Chaudhari, Dynamics of drop impact on solid surface: Experiments and vof simulations, AIChE Journal, 51(1) (2005) 59-78.

[31] A. Clarke, T.D. Blake, K. Carruthers, A. Woodward, Spreading and imbibition of liquid droplets on porous surfaces, Langmuir, 18(8) (2002) 2980-2984.

[32] M. Hilpert, A. Ben-David, Infiltration of liquid droplets into porous media: Effects of dynamic contact angle and contact angle hysteresis, International Journal of Multiphase Flow, 35(3) (2009) 205-218.

[33] N. Zuber, Hydrodynamic aspects of boiling heat transfer, PhD Thesis, University of California at Los Angeles, CA, 1959.

[34] S.G. Liter, M. Kaviany, Pool-boiling chf enhancement by modulated porous-layer coating: Theory and experiment, International Journal of Heat and Mass Transfer, 44(22) (2001) 4287-4311.

[35] C.H. Li, T. Li, P. Hodgins, C.N. Hunter, A.A. Voevodin, J.G. Jones, G.P. Peterson, Comparison study of liquid replenishing impacts on critical heat flux and heat transfer coefficient of nucleate pool boiling on multiscale modulated porous structures, International Journal of Heat and Mass Transfer, 54(15-16) (2011) 3146-3155.

[36] Y.V. Polezhaev, S.A. Kovalev, Modeling heat-transfer with boiling on porous structures, Thermal Engineering, 37(12) (1990) 617-620.

[37] G.A. Powell, Controlled synthesis of cnt-based nanostructures for enhanced boiling and wicking, MS Thesis, Purdue University, West Lafayette, IN, 2009.

[38] M. Denesuk, G.L. Smith, B.J.J. Zelinski, N.J. Kreidl, D.R. Uhlmann, Capillary penetration of liquid droplets into porous materials, Journal of Colloid and Interface Science, 158(1) (1993) 114-120.

[39] L. Bacri, F. Brochard-Wyart, Droplet suction on porous media, The European Physical Journal E: Soft Matter and Biological Physics, 3(1) (2000) 87-97.

[40] J.D. Bernardin, I. Mudawar, C.B. Walsh, E.I. Franses, Contact angle temperature dependence for water droplets on practical aluminum surfaces, International Journal of Heat and Mass Transfer, 40(5) (1997) 1017-1033.

[41] M. de Ruijter, P. Kolsch, M. Voue, J. De Coninck, J.P. Rabe, Effect of temperature on the dynamic contact angle, Colloids and Surfaces A: Physicochemical and Engineering Aspects, 144(1) (1998) 235-243.

\section{Figure captions}

Fig. 1. Schematic diagram detailing the operation of a vapor chamber with a nanostructured capillary wick.

Fig. 2. Digital images of the (a) bare sintered powder sample and CNT-coated sample with (b) $250 \mathrm{~nm}$, (c) $500 \mathrm{~nm}$, and (d) $750 \mathrm{~nm}$ nominal copper coating thicknesses.

Fig. 3. (a) A low-magnification SEM image of CNT-coated sintered powder sample, and highmagnification SEM images of CNT-coated sintered powder samples functionalized with (b) $250 \mathrm{~nm}$, (c) $500 \mathrm{~nm}$, and (d) $750 \mathrm{~nm}$ of nominal copper coating thickness.

Fig. 4. Depth penetration study of $250 \mathrm{~nm}$ nominal copper coating deposited on CNTs synthesized on (a) a flat copper substrate, and (b) a sintered copper powder wick.

Fig. 5. Schematic diagram of (a) the experimental setup, and (b) the heater block and sample assembly.

Fig. 6. (a) Schematic diagram, and (b) photograph of the goniometer setup used for dynamic contact angle measurements. 
Fig. 7. Comparison of boiling curves for the bare sintered powder sample and the CNT-coated samples functionalized with $250 \mathrm{~nm}, 500 \mathrm{~nm}$ and $750 \mathrm{~nm}$ nominal thickness of copper coating. The maximum heat flux values in each case represent approximate dryout points.

Fig. 8. Comparison of overall thermal resistance for the bare sintered powder sample and the CNT-coated samples functionalized with $250 \mathrm{~nm}, 500 \mathrm{~nm}$ and $750 \mathrm{~nm}$ nominal thickness of copper coating.

Fig. 9. Comparative partial dryout area (highlighted by a dashed line) for CNT-coated samples functionalized with (a) $250 \mathrm{~nm}$, (b) $500 \mathrm{~nm}$, and (c) $750 \mathrm{~nm}$ nominal thickness of copper coating.

Fig. 10. (a) Digital, (b) low-magnification SEM, and (c), (d) high-magnification SEM images of the external region of the $750 \mathrm{~nm}$ sample wick surface after thermal testing. (e), (f) Low- and (g) highmagnification SEM images of the dryout area of the wick surface after thermal testing.

Fig. 11. Three phases of droplet infiltration on a porous surface, according to [32]. During the increasing drawing area (IDA) phase, the drawing area increases from $\mathrm{A}_{1}$ to $\mathrm{A}_{2}$ while the contact angle decreases to the equilibrium advancing contact angle $\theta_{a}$. The contact angle continues to decrease from $\theta_{a}$ to the equilibrium receding contact angle $\theta_{r}$ at a constant drawing area in the constant drawing area (CDA) phase. During the decreasing drawing area (DDA) phase, the drawing area decreases until the droplet is completely absorbed.

Fig. 12. Representative stages of droplet infiltration for the $250 \mathrm{~nm}$ coated sample.

Fig. 13. Variation of drawing radius (in $\mathrm{mm}$ ) and contact angle (in deg) as a function of time during droplet infiltration on bare, $250 \mathrm{~nm}$ and $750 \mathrm{~nm}$ samples.

\section{Figures}

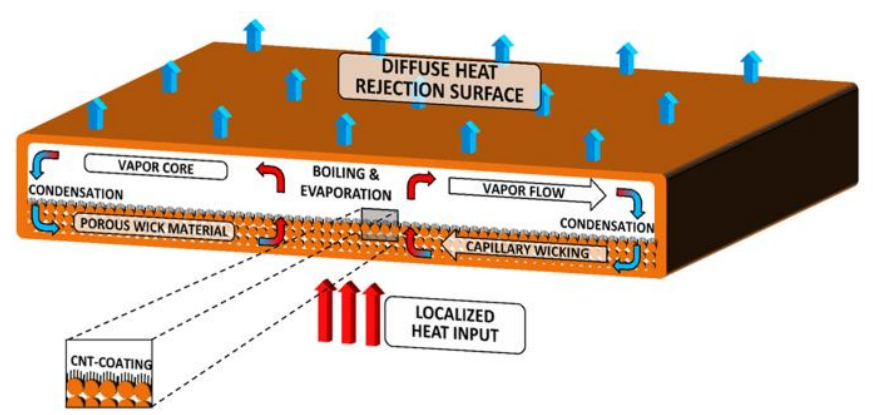

Figure 1 

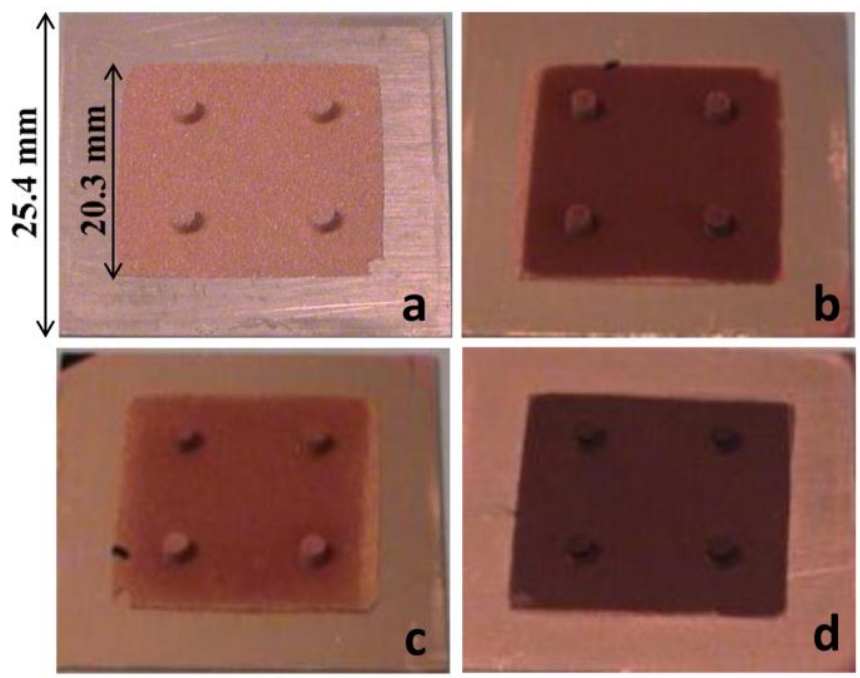

Figure 2

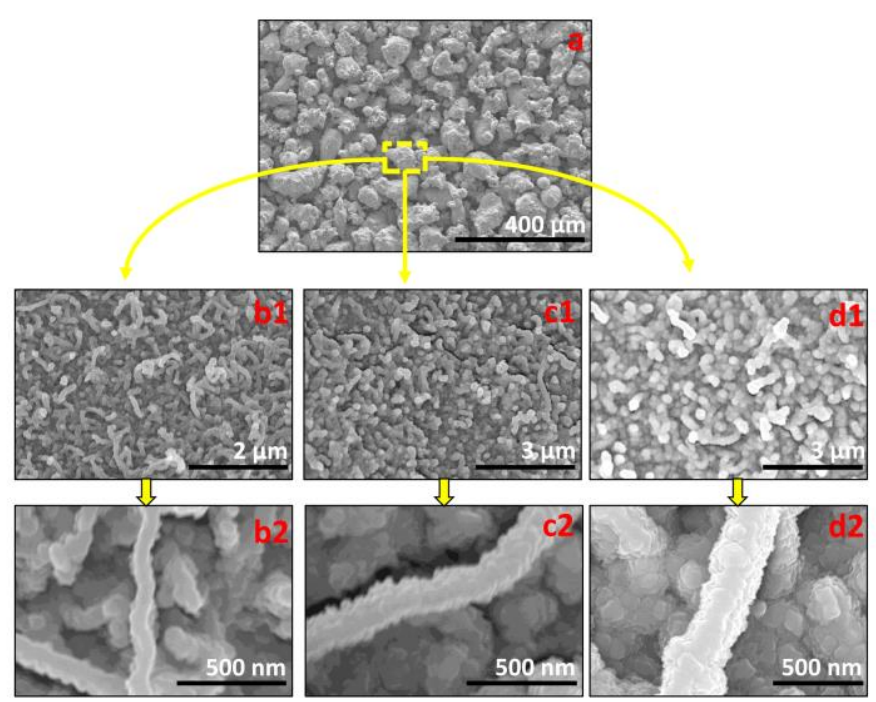

Figure 3

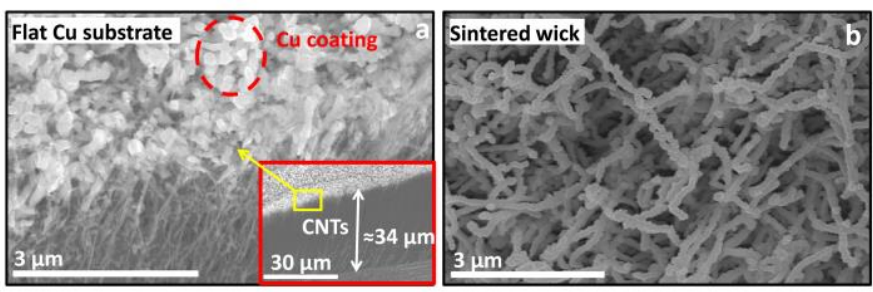

Figure 4 


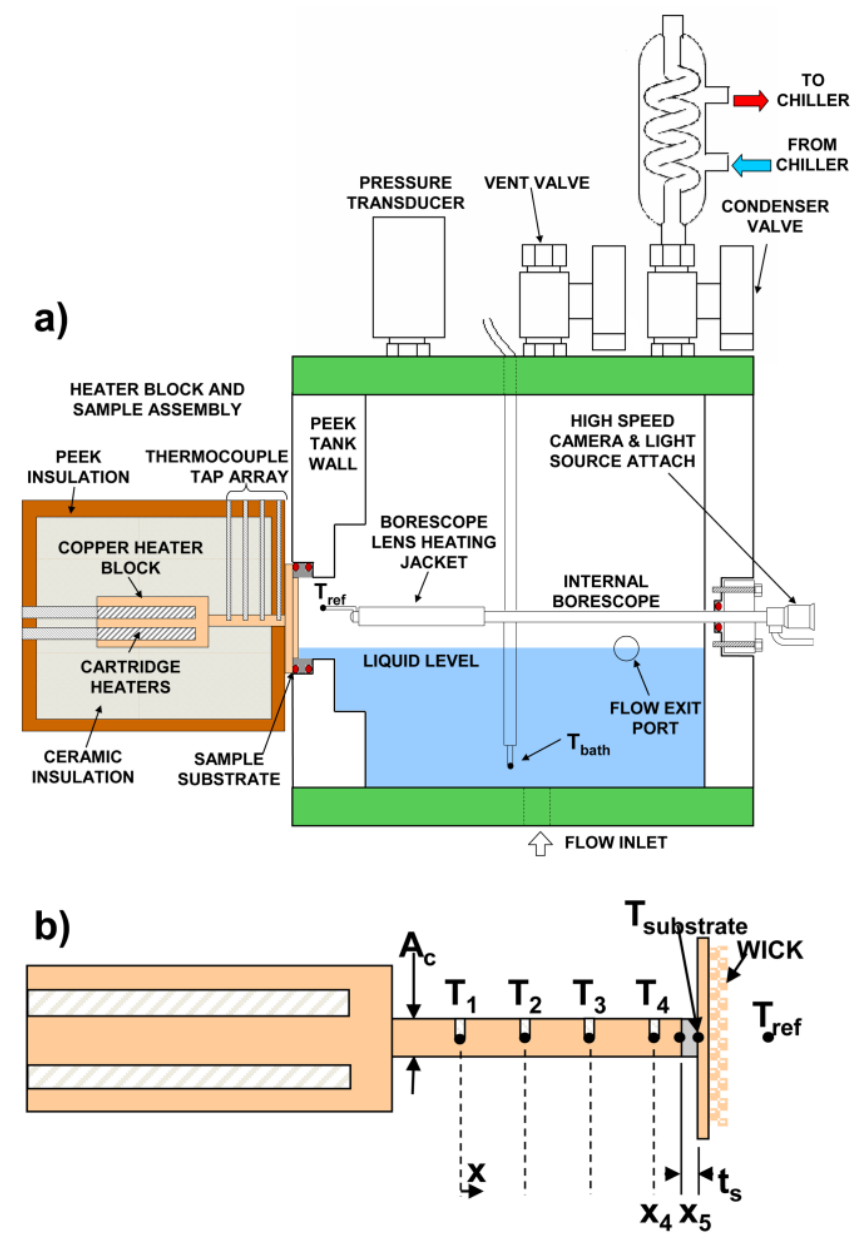

Figure 5

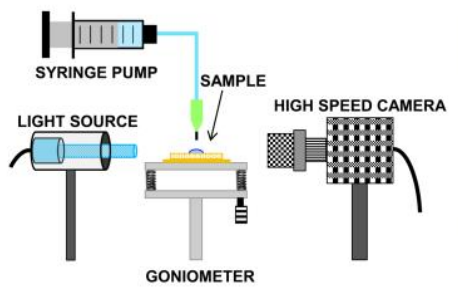

a)

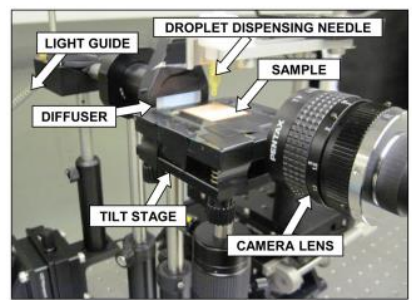

b)

Figure 6 


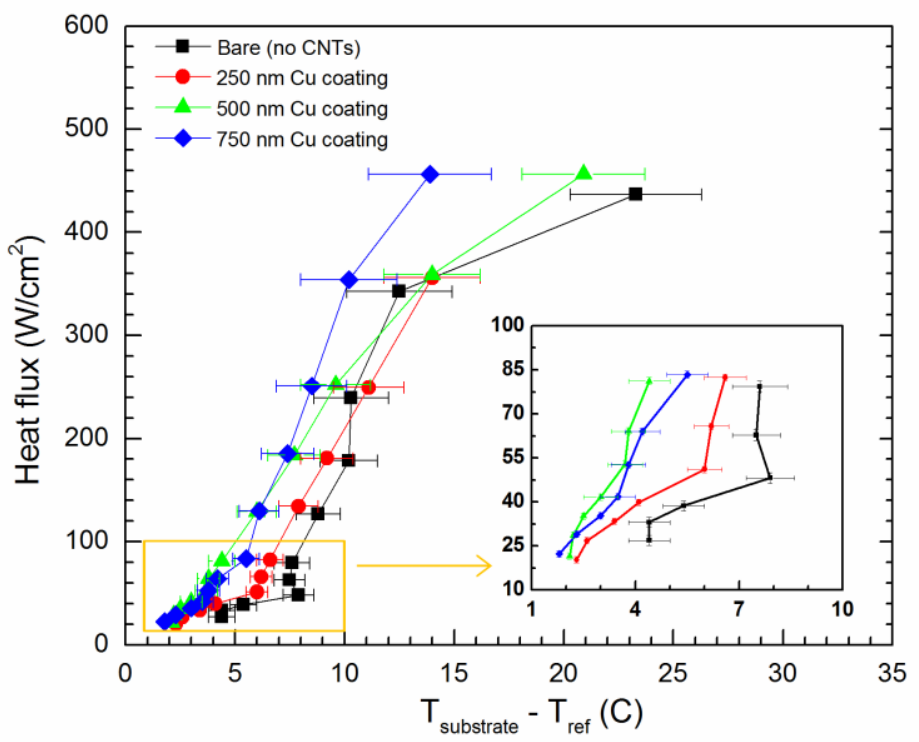

Figure 7

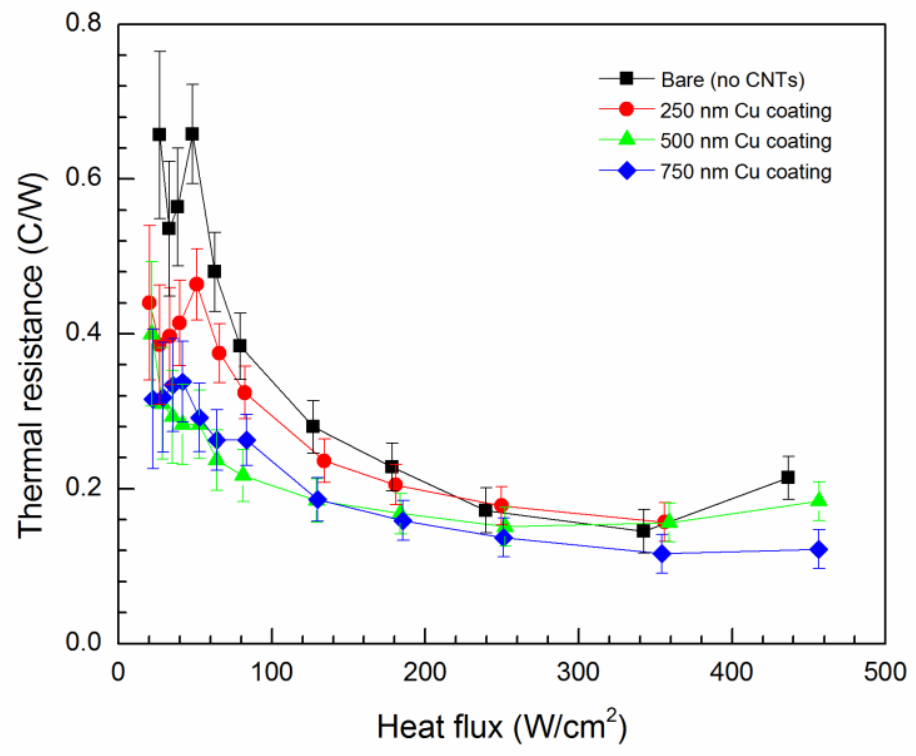

Figure 8
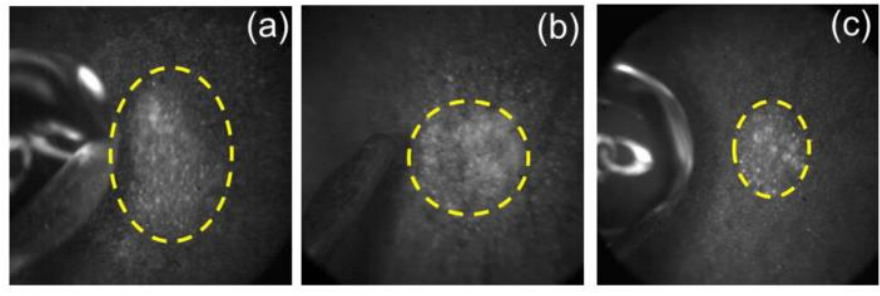

Figure 9 


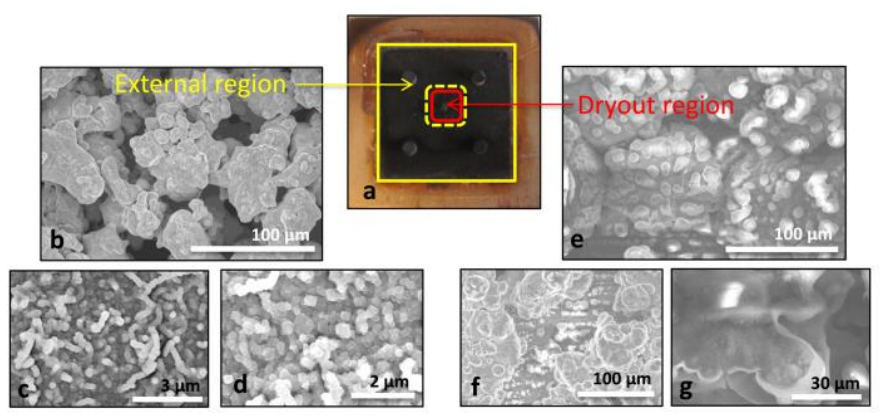

Figure 10

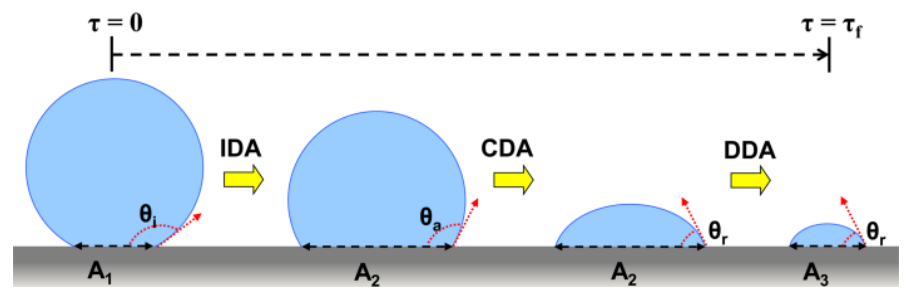

Figure 11

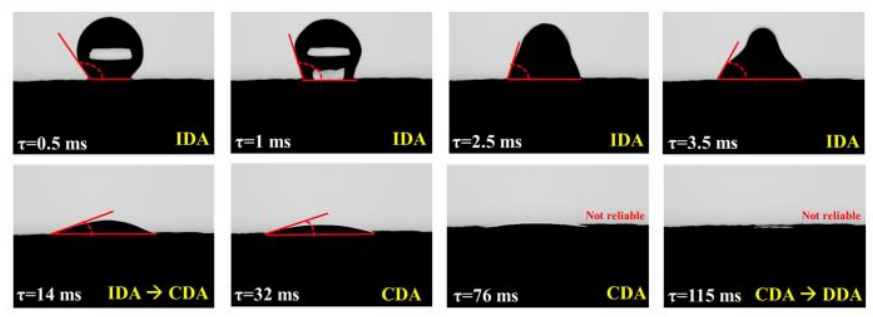

Figure 12

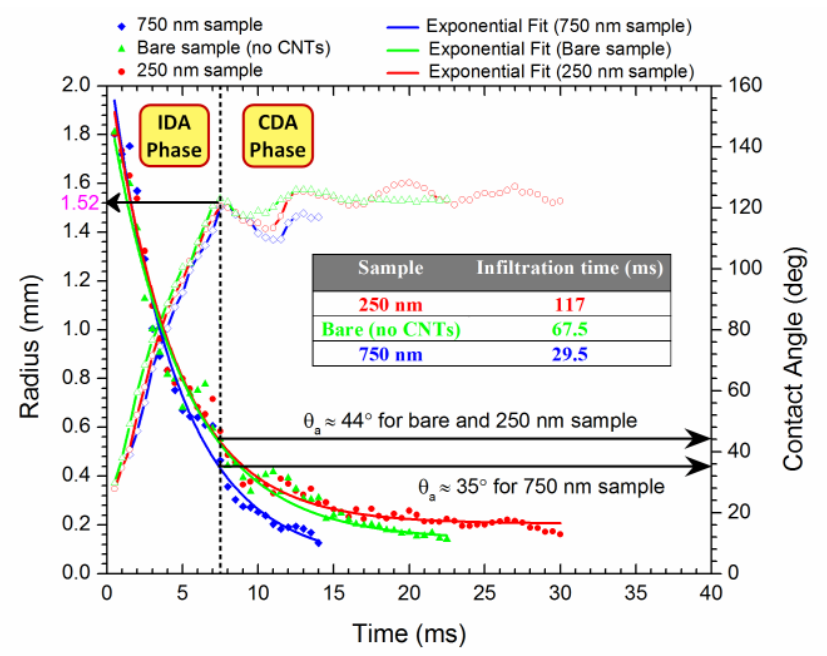

Figure 13 